\title{
SEM AVISO PRÉVIO
}

\section{Kelly Menezes Crespi}

Universidade de Caxias do Sul

\section{Juliana Raquel de Souza Luchesi}

Universidade de Caxias do Sul

\section{Sylvia Maria Azevedo Roesch}

Universidade de Caxias do Sul

\section{Pelayo Munhoz Olea}

Universidade de Caxias do Sul

\section{Histórico}

A empresa Princesas Calçados $\operatorname{Ltda}^{1}$ fica situada em uma pequena cidade do interior do estado do Rio Grande do Sul e iniciou suas atividades em 1970.

Uma das maiores preocupações da Princesas é possuir sempre tecnologia de última geração para dar suporte à administração e fábrica. Nestes 40 anos, a Princesas adequou suas instalações físicas e buscou matéria-prima para produzir novos e melhores calçados. Também solidificou um Departamento

\footnotetext{
${ }^{1}$ Os nomes da empresa, dos personagens e da cidade são fictícios para preservar as fontes do caso real.
}

\section{CFGV-EAESP/RAE 2011}

Todos os direitos reservados. Permitidas a citação e a reprodução parcial ou total, desde que identificada a fonte. Em caso de dúvidas, consulte a Redação: gvcasos.redacao@fgv.br; (11) 3799-3717 
de Tecnologia da Informação para atender as suas demandas internas e externas. Sendo assim, foi necessário contratar profissionais especializados nesse assunto.

Atualmente, o Departamento de TI conta com 40 funcionários que estão divididos em células para atender a todas as áreas de negócio da empresa. Em torno de 60\% das demandas de criação de sistemas são totalmente atendidas dentro do Departamento de TI. Para os $40 \%$ restantes, é solicitado auxílio de profissionais terceirizados (ver anexo 1).

A empresa não possui um Departamento de RH muito desenvolvido. Ele presta essencialmente atividades burocráticas de admissão, demissão, folhas de pagamento, entre outras atividades rotineiras. Recentemente, a empresa vem desenvolvendo um trabalho de mapeamento das oportunidades dentro de cada departamento.

Contudo, ainda não há práticas e políticas definidas no que se refere ao relacionamento com os recursos humanos da empresa.

\section{O contexto}

Janeiro de 2010, 7h30 da manhã. Mais uma sexta-feira ensolarada e, ao que tudo indicava, o final de semana seria igual. Os funcionários do Departamento de Informática da empresa Princesas Calçados Ltda, empresa que fabrica calçados e fica situada no interior do estado do Rio Grande do Sul, chegavam ao trabalho. Em clima de encerramento das atividades semanais e início de final de semana, todos estavam sorridentes.

Ricardo da Silva Borges tem 42 anos e trabalha na Princesas há 12 anos. Antes de chegar à Princesas Calçados, ele trabalhou para um fornecedor da empresa fazendo implantação de ERPs (Enterprise Resource Planning) em vários clientes, até o momento em que foi convidado pela Princesas Calçados Ltda para tornar-se seu funcionário. Ricardo iniciou suas atividades como analista de negócios, assim estava constantemente junto aos usuários da empresa fazendo levantamentos e especificações de novas funcionalidades a serem alteradas ou incluídas no ERP da empresa. Contudo, no mesmo ano de sua admissão (1998), recebeu um novo convite na Princesas, mas agora para assumir 
o cargo de supervisor da Célula de Distribuição e Finanças. Em sua nova função, Ricardo planejava, acompanhava e monitorava as atividades e resultados de sua equipe, formada por cinco funcionários. Ricardo sempre gostou muito de trabalhar na Princesas porque os colegas eram parceiros para todas as horas. Ricardo é natural de uma grande capital e aprendeu a gostar da cidade pequena porque todos são conhecidos ou amigos.

Antes de trabalhar na Princesas, Gustavo Saldanha, que tem 44 anos, trabalhava como office boy para um escritório de contabilidade da cidade. Ele começou a trabalhar na Princesas Calçados Ltda em 1987, como digitador, após foi promovido a operador de sistemas e, em 1993, tornou-se analista de negócios. Já no ano de 2002, ele recebeu a esperada oportunidade de trabalhar em um cargo de gerência. Gustavo assumiu o cargo de coordenador de sistemas, no qual tinha as responsabilidades de gerenciar sua equipe, que contava com 20 funcionários, assegurar as diretrizes para a equipe de sistemas e gerenciar a execução e implementação dos projetos realizados pela TI. Para assumir esse novo cargo, Gustavo recebeu poucos e curtos treinamentos sobre liderança, que foram ministrados por funcionários do Departamento de RH da empresa.

Durante quatro anos (entre 1998 e 2002), Ricardo foi o supervisor de Gustavo, mas, ainda em 2002, Gustavo assumiu o cargo de coordenador de sistemas e tornou-se coordenador das atividades de Ricardo.

Aparentemente, para os demais colegas do Departamento de TI, sempre houve um bom relacionamento entre Ricardo e Gustavo. Ricardo era um homem que gostava de mudanças e Gustavo, por sua vez, tinha preferência por zelar pela estabilidade.

Suas experiências pessoais e profissionais eram bem diferentes, o que resultava em frequentes conflitos interpessoais, em que cada um defendia seu ponto de vista e dificilmente entravam em consenso (ver anexo 2). 


\section{O inesperado}

O dia no Departamento de TI transcorreu normalmente. As metas da semana foram atingidas e novas atividades para a próxima semana foram agendadas. O sinal de final de expediente soou e os funcionários saíram. Contudo, Gustavo aproximou-se de Ricardo e pediu a ele que comparecesse em sua sala. A conversa começou com um tom de voz diferente. Gustavo inicia a conversa:

- Vamos direto ao assunto. Agradecemos seus serviços prestados à Princesas, mas a partir de hoje não precisamos mais deles.

- Você está querendo dizer que estou demitido? Posso saber o motivo da minha demissão?

- Isso mesmo. A justificativa para sua demissão é falta de humildade.

- Por que você nunca me chamou para me dar um feedback?

- Porque... [pausa] não era necessário. A empresa não tem essa política de dar feedbacks.

Após o aviso ser feito, Gustavo acompanhou Ricardo enquanto ele pegava seus pertences pessoais e ia embora.

Ricardo sentiu uma mistura de sentimentos. Sentia raiva por não compreender exatamente o que havia acontecido, desespero por não saber como falar isso para sua família e preocupação por estar ciente de que já tinha 42 anos e, para uma área técnica, isso é o fim da carreira.

Segunda-feira, 7h35 da manhã. Os funcionários retornaram à Princesas e, ao checar seus $e$ mails, não entendiam o que havia acontecido. Havia apenas um sucinto e-mail comunicando que o colega Ricardo da Silva Borges não fazia mais parte do quadro de funcionários e que qualquer assunto tratado por ele anteriormente devia ser repassado ao seu superior imediato. No Departamento de TI, instalou-se um clima de tristeza e, durante essa semana, notou-se que as metas das equipes não foram atingidas.

Alguns funcionários agiam como se nada houvesse acontecido e outros comentavam pelos corredores seus sentimentos de frustração e injustiça. Quando ocorre uma demissão no Departamento de TI, nenhum funcionário tem coragem de perguntar a Gustavo ou a qualquer outro superior mais 
detalhes referentes ao ocorrido. Sendo assim, instala-se a "rádio peão" e várias dúvidas e boatos se alastram pelo departamento.

Na sala do cafezinho, em torno das 10 h00 da manhã da segunda-feira, Margarida Inês Suzin, que trabalha na Princesas há 27 anos e sempre trabalhou no atendimento aos usuários (Help Desk), comentou com um colega:

"Aqui não recebemos nenhum retorno de nossos superiores. Nunca sabemos o que está bom ou ruim nas atividades que a gente realiza. Acho que eles têm medo de que a gente tenha o direito de avaliá-los [chefes] também. Fico chateada com a frieza com que ocorrem as demissões. Cada um de nós é apenas mais um. Não deu mais, então fora...".

Eduardo Mendes, que tem 55 anos de idade e há 15 anos presta serviços na Princesas, concordou com Margarida e completou seu comentário:

“Aqui não importa se você está preparado para cumprir uma tarefa. Cumpra-a de qualquer maneira. Eles simplesmente não compreendem os benefícios de se comunicar claramente e de incentivar o trabalho em equipe. Também notei, Margarida, que depois de 2008 [entrada da empresa na bolsa de valores] o comprometimento com os recursos humanos da empresa piorou".

Assim, entre comentários e boatos, as semanas transcorrem, mas ficam no ar algumas perguntas, e os funcionários do Departamento de TI sentem-se cada vez mais inseguros. Quem será o próximo a ser demitido? Quando será a próxima demissão? Qual será a justificativa da demissão?

Enquanto isso, Gustavo encontra-se na sala do Gerente de TI, Evandro Albertoni, que administra o departamento há 29 anos. Evandro, quando adolescente, trabalhou em uma empresa que era prestadora de serviços para a Princesas Calçados Ltda. Ele destacou-se nessa empresa por ser uma pessoa autodidata e logo foi convidado pela Princesas a fazer parte do seu quadro de funcionários. 
Gustavo e Evandro discutem sobre o perfil do novo supervisor que substituirá o colega Ricardo, ou seja, o assunto demissão já era passado e não seria mais referido.

Gustavo então falou: "Sou da opinião de que o novo supervisor deve ver conflitos de maneira positiva, porque eles nos fazem sair da zona de conforto. Nesse caso, ele deve ter conhecimento e habilidade para utilizar as ferramentas de gestão apropriadas para cada situação. O supervisor deve ser uma pessoa que se adapte facilmente às situações e consiga trabalhar com pessoas, integrando objetivos pessoais aos organizacionais na busca de melhores resultados”.

Albertoni discute com Gustavo todos os requisitos necessários para a nova vaga e solicita que a descrição da vaga seja encaminhada para o Departamento de Recrutamento e Seleção para que iniciem a seleção. 


\section{Anexo 1}

\section{Organograma da empresa}

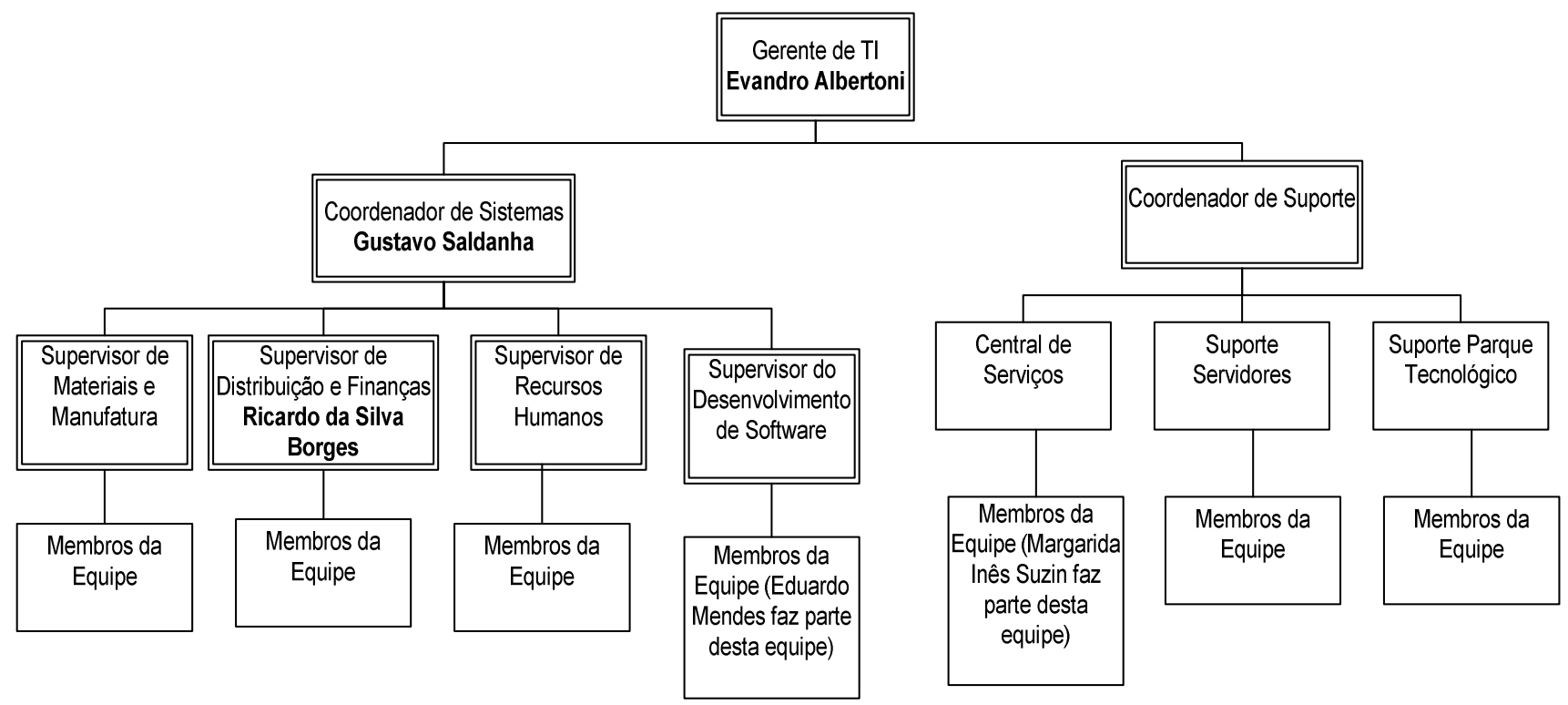

Fonte: documentos da empresa 


\section{Anexo 2}

\section{Mapa de Oportunidades do Departamento de TI da empresa}

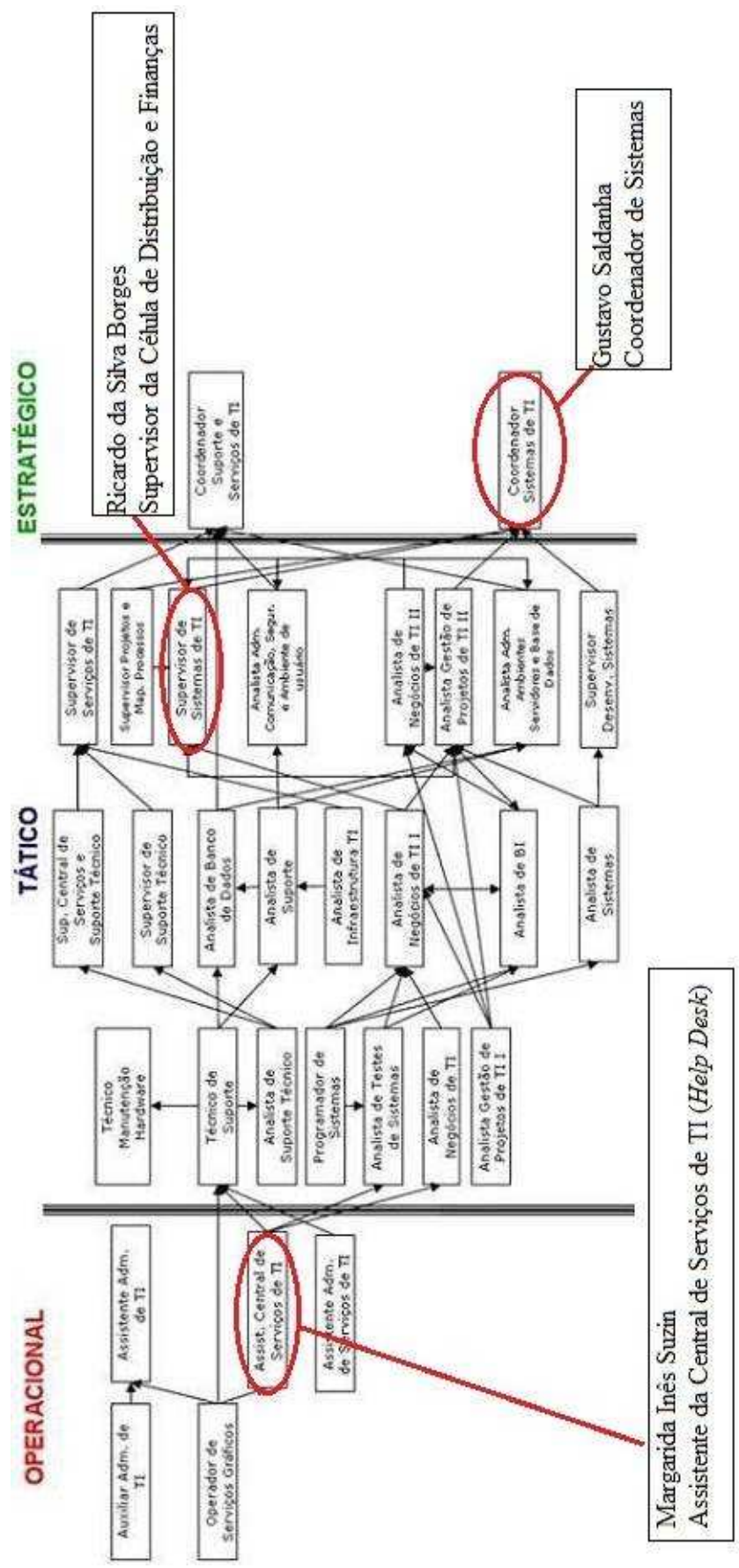

Obs: Os cargos estão divididos em operacional, tático e estratégico. Os cargos dos personagens principais estão destacados. Fonte: documentos da empresa 